\title{
A Simple Enzymatic Preparation of 2',3'-Di-O- Acetylnucleosides Through a Lipase Catalyzed Alcoholysis
}

\author{
Alejandra Zinni ${ }^{1}$, Alejandro Schmidt ${ }^{1}$, Mariana Gallo ${ }^{2}$, Luis Iglesias ${ }^{1}$ and Adolfo Iribarren ${ }^{1,2}$ \\ ${ }^{1}$ Centro de Estudios e Investigaciones, Universidad Nacional de Quilmes - Roque Sáenz Peña 180 - \\ (1876) Bernal - Buenos Aires, Argentina \\ ${ }^{2}$ INGEBI (CONICET) - Vuelta de Obligado 2490 - (1428) - Buenos Aires, Argentina \\ E-mail: leiglesias@unq.edu.ar
}

\begin{abstract}
Several 2',3'-di-O-acetylnucleosides (2a-d) were obtained regioselectively through a Candida antarctica B lipase catalyzed alcoholysis.
\end{abstract}

\section{Introduction}

Much effort has been devoted to the synthesis of nucleoside analogues as most of the antiviral agents used at present against extensive viral affections belong to this family of compounds [1]. Due to the polyfunctional nature of nucleosides, selective transformations are usually required to prepare these molecules in good yields. However, such reactions are frequently difficult to carry out satisfactorily by means of traditional synthetic procedures [2]. For instance, in the synthesis of oligonucleotides and nucleosides prodrugs, regioselective protection and deprotection of hydroxyl groups are carried out through multy-steps processes.

Enzymes have become nowadays well-recognized regio- and stereoselective catalysts in synthetic chemistry [3], and lipases are one of the most useful biocatalysts due to their efficiency, easy work up and stability in organic solvents. These facts prompted us to study lipase-catalyzed deacylation of nucleosides 1a-d through a Candida antarctica B lipase (CAL) catalyzed alcoholysis:

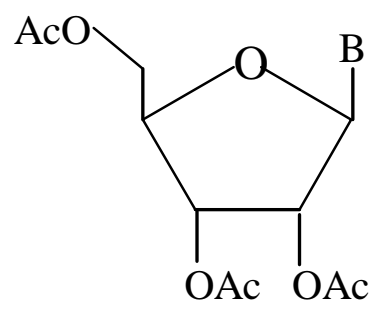

1 a-d
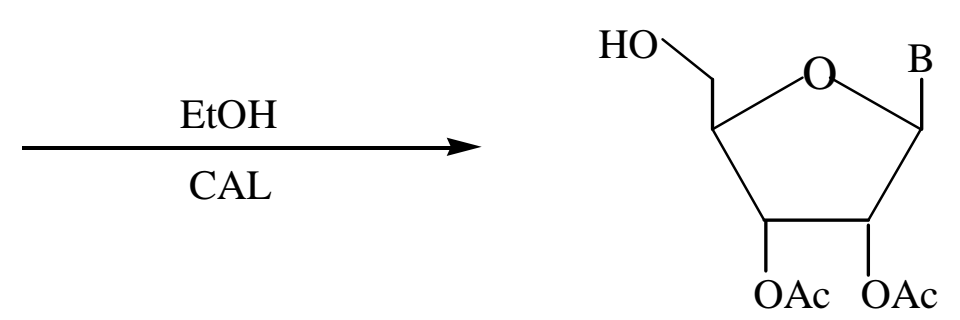

2 a-d

Scheme. a R= H, B= 1-uracyl; b R= $\mathrm{CH}_{3}, \mathrm{~B}=1$-uracyl; c R= H, B=9-hypoxantyl; d R= H, B=9-guanyl. 


\section{Experimental}

The alcoholysis shown in the Scheme were performed at $200 \mathrm{rpm}$ and $28^{\circ} \mathrm{C}$. The reaction mixtures were analyzed by both TLC and HPLC, using a C-18 column. After a convenient time was reached, the enzyme was filtered off and products 2a-d were isolated by column chromatography, affording satisfactory spectral data $\left({ }^{1} \mathrm{H}\right.$ and $\left.{ }^{13} \mathrm{C} \mathrm{NMR}\right)$.

\section{Results and Discussion}

Although the reactions depicted in the Scheme were studied employing three lipases: Lipozyme ${ }^{\mathrm{R}}$ (Mucor miehei lipase), Candida rugosa lipase and CAL, only the latter exhibited activity. With this biocatalyst, compounds $\mathbf{2 a - d}$ could be obtained regioselectively in good yields. The ethanol/nucleoside ratio and the solvent showed a dramatic effect on the selectivity and the yield of the biotransformation.

In contrast to the non enzymatic synthesis of compounds $\mathbf{2 a , c , d}$, which requires three steps, the regioselective enzymatic alcoholysis presented herein avoids one step and is carried out under simple and mild conditions.

\section{References and Notes}

1. Périgaud, C.; Gosselin G.; Imbach, J.L. Nucleosides Nucleotides 1992, 11, 903.

2. Hanrahan J.R.; Hutchinson, D.W. J.Biotechnol. 1992, 23, 193.

3. Wong C.H.; Whitesides, G.M. Enzymes in synthetic organic chemistry; Elsevier Science Ltd.: Oxford, 1994, Cap. 2.

4. Sachder, H.S.; Starkovsky, N.A. Tetrahedron Letters 1969, 7, 33.

5. Iglesias, L.E.; Zinni, A.; Gallo, M.; Iribarren, A. Submitted for publication. 